\title{
The role of interventional oncology in the treatment of colorectal cancer liver metastases
}

\author{
Maria Tsitskari, Dimitris Filippiadis, Chrysostomos Kostantos, Kostantinos Palialexis, Periklis Zavridis, \\ Nikolaos Kelekis, Elias Brountzos
}

Attikon University Hospital, National and Kapodistrian University of Athens, Greece

\begin{abstract}
Colorectal cancer is a leading cause of death both in Europe and worldwide. Unfortunately, 20-25\% of patients with colorectal cancer already have metastases at the time of diagnosis, while 50$60 \%$ of the remainder will develop metastases later during the course of the disease. Although hepatic excision is the first-line treatment for patients with liver-limited colorectal metastases and is reported to prolong the survival of these patients, few patients are candidates. Locoregional therapy encompasses minimally invasive techniques practiced by interventional radiology. Most widely used locoregional therapies include ablative treatments (radiofrequency ablation, microwave ablation) and transcatheter intra-arterial therapies (transarterial chemoembolization, and radioembolization with yttrium-90).
\end{abstract}

Keywords Colorectal cancer, treatment, thermal ablation, intra-arterial therapies

Ann Gastroenterol 2019; 32 (2): 1-9

\section{Introduction}

Colon cancer is the third most common type of cancer diagnosed in patients worldwide and is a leading cause of death both in Europe and worldwide [1,2]. Researchers have recognized several lifestyle behaviors that heighten the risk of this cancer among men and women: poor diet, smoking, physical inactivity, obesity, and use of carcinogens in processed foods [3]. However, over the past decade, the incidence and mortality of colorectal cancer have decreased in both men and women and the clinical outcome of metastatic colorectal cancer patients has improved. This was made possible by strategic improvements and the development of innovative and sophisticated diagnostic and therapeutic tools, which include both invasive procedures and noninvasive techniques [4].

Unfortunately, 20-25\% of patients with colorectal cancer already have metastases at the time of diagnosis, while 50-60\% of the remainder will develop metastases later during the course of the disease $[5,6]$. During the metastatic stage, colon or rectal cancer often spreads systemically to the liver followed by lungs,

Second Department of Radiology, Unit of Vascular and Interventional Radiology, Attikon University Hospital, National and Kapodistrian University of Athens, Greece

Conflict of Interest: None

Correspondence to: Maria Tsitskari MD, EBIR, Athens, Greece, e-mail: mariadote@hotmail.com

Received 10 July 2018; accepted 20 November 2018; published online 14 December 2018

DOI: https://doi.org/10.20524/aog.2018.0338 bones or any other part of the body. Surgical resection is widely accepted as the first-line treatment for patients with liverlimited colorectal metastases and is reported to prolong the survival of these patients. Studies have shown that the 5-year survival rate is over $50 \%$ in patients with hepatic metastases treated successfully with resection $[5,7,8]$. Regrettably, about $80-90 \%$ of colorectal liver metastases (CRLM) are deemed not suitable for resection because of complex tumor anatomy (metastasis site, number, and size), extrahepatic disease and the patient's deteriorating health condition [9]. Moreover, up to $80 \%$ of patients develop liver recurrence up to 10 years post surgery, the majority within the first 2 years [10]. However, with the evolution of new chemotherapeutic agents, the advent of immunotherapy and targeted minimally invasive therapies, clinicians are now incorporating a multidisciplinary approach to treat patients with unresectable disease or potentially resectable disease, to treat recurrences and prolong these patients' survival [11].

Additionally the role of imaging in colon cancer has evolved significantly, with the development of techniques that provide high accuracy in establishing localized invasive treatments. Consequently, new therapeutic techniques have been exploited by clinicians to incorporate hi-tech imaging modalities for targeted removal of malignant tissues and cells [12]. Various interventional radiology procedures are considered as either alternatives to surgery or ancillary treatment methods in the interdisciplinary therapy management of metastatic colorectal patients. Most widely used treatment methods include percutaneous ablation (radiofrequency, microwave), transarterial chemoembolization (TACE), and selective internal radiation therapy [13]. For some patients, locoregional 
therapies can alternatively be used as symptomatic or palliative treatments.

Given the wide spectrum of alternative or ancillary therapies to resection, this paper will focus on the energy-based ablation techniques, specifically the utilization of radiofrequency ablation (RFA) and microwave ablation (MWA), as well as intraarterial therapies, chemoembolization and radioembolization, and will discuss the extent to which each of these techniques is effective for the treatment of colorectal metastases.

\section{Thermal ablation}

In recent years, there has been growing interest in minimally invasive local ablative therapies to treat lesions not amenable to surgery as well as resectable lesions in poor surgical candidates [14].

\section{Indications}

The indications for ablation of CRLM are in line with the accepted definition of oligometastatic disease. Patients with a limited number $(<4)$ of small-sized $(<5 \mathrm{~cm}$ in largest diameter) metastases that are not amenable to surgery (or the patient refuses) and can be treated with a curative intent are good candidates for percutaneous image-guided ablation therapy. Image-guided ablative therapies, percutaneous or intraoperative, can also be applied in combination with surgical treatment strategies to improve resectability in patients who fail to meet the resection criteria.
RFA

RFA induces thermal damage through frictional heating due to ionic oscillation by a high-frequency alternating current $(375-500 \mathrm{kHz})$ from monopolar or bipolar radiofrequency systems. The positive attributes of RFA are that it is a simple, repeatable, standardized and low-risk therapy. However, it is limited by an active heating zone of a few millimeters, while its impedance increases as the tissue boils and char residue is produced, since char insulates against electrical signals. The exposure of tumor cells to a temperature of approx. $50^{\circ} \mathrm{C}$ for 4-6 min induces cytotoxicity, while between $60-100^{\circ} \mathrm{C}$ the proteins in the cells start to coagulate irreversibly [15]. At $100^{\circ} \mathrm{C}$, water evaporates from the tissues, causing desiccation, and the resultant electrical impedance limits the volume of thermal transmission. In addition, especially near large blood vessels, heating facilitates a heat sink effect to reduce the efficacy of cell death by RFA [16].

There are several studies reporting the safety and efficacy of RFA for the treatment of unresectable CRLM (Table 1). Solbiati et al reported 3-, 5- and 10-year survival rates of 69\%, $48 \%$ and $18 \%$, respectively, in a series of 202 CRLM treated with percutaneous ablation; the major complication rate was $1.3 \%$ and there were no procedure-related deaths [17]. Gillams \& Lees also reported the results of ablation guided by computed tomography or ultrasound, with single or clustered water-cooled electrodes, in 167 patients with CRLM; the 5-year survival rate was $30 \%$ and the major complication rate $4 \%$ [18]. These results are close to the 5-year survival rates of surgical resection $(33-58 \%)[8,19]$.

Factors that limit RFA success rates include lesion location, size, tumor-free margin and number of lesions. Wang et al in

Table 1 Literature highlights of thermal (RFA and MWA) ablation for colorectal liver metastases

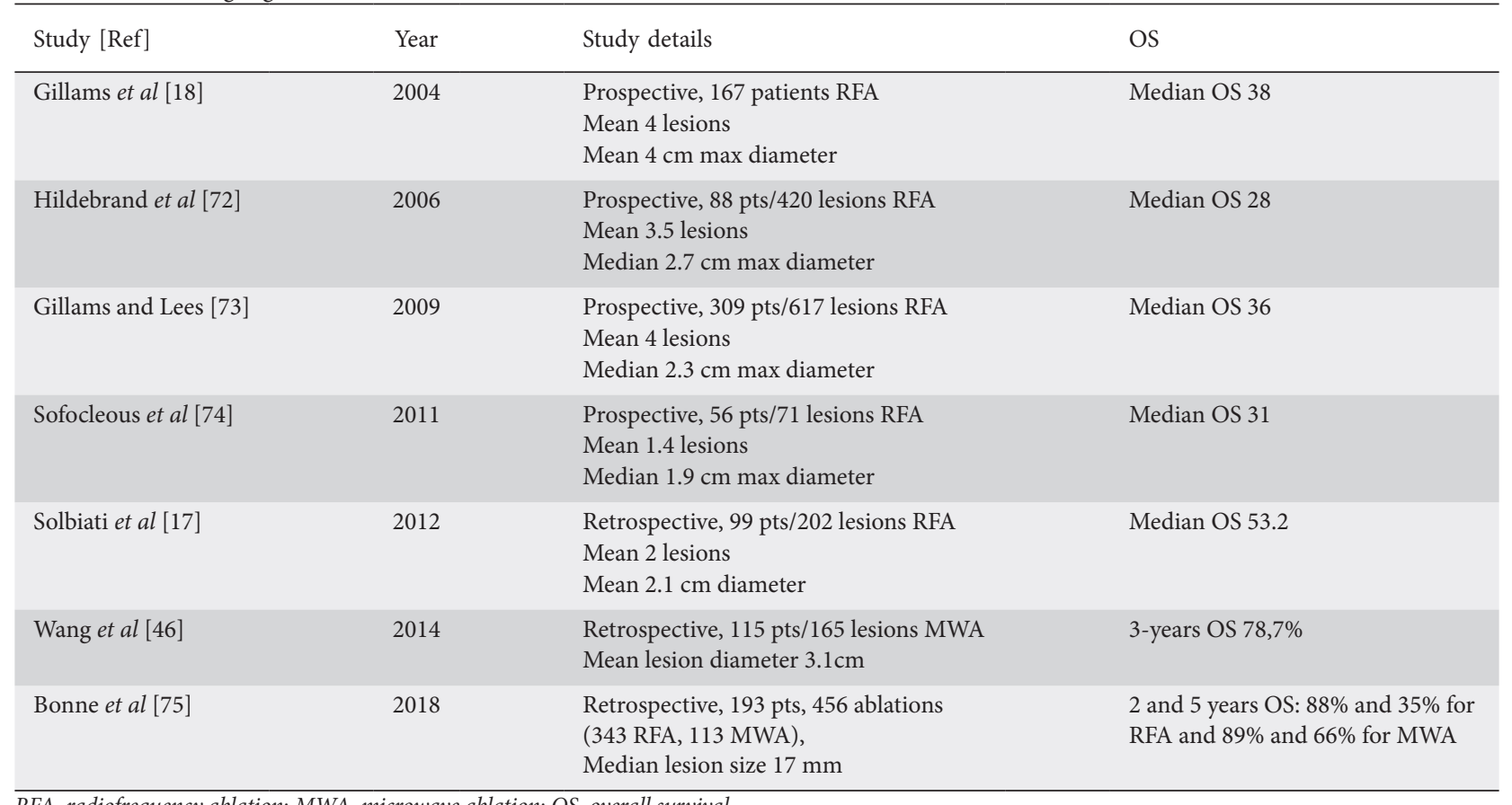

RFA, radiofrequency ablation; $M W A$, microwave ablation; OS, overall survival 
2013 emphasized the presence of an irregular ablation defect and the need for at least a $5 \mathrm{~mm}$ margin surrounding the tumor homogeneously to attain good local tumor control [20]. It is generally advocated that the ideal lesions for consistently successful ablation are those $<3 \mathrm{~cm}$ in maximum diameter. Accordingly, Shady et al have suggested that RFA may not be as effective for tumor size $>3 \mathrm{~cm}$ [21]. Van Tilborg et al reported the results of RFA ablation in 237 treated lesions in 100 patients; local RFA site recurrence was 5.6\%, 19.5\% and $41.2 \%$ for tumor diameters $<3 \mathrm{~cm}, 3-5 \mathrm{~cm}$ and $>5 \mathrm{~cm}$, respectively [22]. In addition, centrally located lesions recurred more often than peripheral ones: $21.4 \%$ (21/98) vs. $6.5 \%$ (9/139) [21]. However, with more experience and more sophisticated tools of ablation there is a tendency to increase the cutoff point for potential complete ablation. So there are authors who suggest that, depending on their location, accessibility and the ablation protocol used, lesions up to $5 \mathrm{~cm}$ can also be treated effectively with low local recurrence rates. Hammil et al reported a 3\% local recurrence rate for tumors $<3 \mathrm{~cm}$ and a $4 \%$ recurrence rate for 3-5 $\mathrm{cm}$ tumors [23].

The number of lesions to be treated can also adversely affect the result. Ablation of solitary metastases, similarly to the resection literature, has been related with high local tumor control. Kim et al reported 5-year survival of 51\%, while Gilliams et al reported a 5-year survival rate of 54\% in 40 patients with solitary lesions up to $4 \mathrm{~cm}[24,25]$.

Some authors claim that RFA can be used as first-line treatment instead of resection, since it is equally safe and effective, with comparative median disease-free survival, minimal invasiveness and shorter hospital stays, especially for small and medium size lesions $[18,22,24,26,27]$. To date, there are several retrospective studies but no prospective randomised trials regarding RFA ablation vs. surgical resection for CRLM. Most of these studies report a lower recurrence rate after hepatic resection; however, it should be noted that the selection of the ablation and resection groups was not randomized. In the majority of these studies ablation was performed for lesions not amenable to surgical resection, or for resectable lesions in patients with poor general condition and multiple comorbidities. Nevertheless, subgroup analysis showed similar survival outcomes for RFA and hepatic resection in patients with tumor size $<3 \mathrm{~cm} \mathrm{[28].} \mathrm{Lee} \mathrm{et} \mathrm{al} \mathrm{[29]} \mathrm{and} \mathrm{other} \mathrm{authors}$ claim that, while RFA may be a better therapeutic approach for unresectable single and small $(\leq 2 \mathrm{~cm})$ lesions and the survival rates are comparable to hepatectomy and chemotherapy, it cannot replace resection, particularly in cases with tumor diameters $>3 \mathrm{~cm}[24,30-34]$.

Other researchers have outlined the value of combination therapies, so that resection and RFA complement each other for better results in terms of reducing recurrence, as opposed to utilizing them independently [19,35]. Likewise, other researchers have suggested the combined use of chemotherapy and RFA [36,37] to prolong survival and decrease local recurrence rates in patients with CRLM. The CLOCC study was the first to prospectively evaluate RFA plus chemotherapy [38]. This study showed that radiofrequency plus chemotherapy is clearly superior to systemic chemotherapy in terms of progression-free survival (PFS) and overall survival (OS) in colorectal cancer patients with inoperable liver metastases. Median OS was 45.3 months in the RFA arm vs. 40.5 months in the chemotherapy-alone arm, while the 8 -year OS was $35.9 \%$ vs. $8.9 \%$ in the RFA arm and the 8 -year PFS was $22 \%$ vs. $2 \%$ [38].

\section{MWA}

During the past several years MWA has gained acceptance as a favorable alternative to RFA and in some cases a preferred choice of ablation modality. Microwave systems use an electromagnetic signal to generate heat. Current microwave manufactures operate at frequencies between 900-2450 MHz. At this frequency range, electromagnetic microwaves heat matter by vigorous agitation of water molecules in the tissues, producing friction and heat. This results in cellular death via coagulation necrosis [38]. MWA features several advantages compared with RFA ablation, such as higher intratumoral temperatures, faster heating over a larger volume of tissues, incorporation of multiple applicators simultaneously and less procedural pain (Fig. 1). In contrast to RFA, MWA generates electromagnetic waves that produce thermal necrosis via molecular friction. As a result, resistance to heat sink effect, high impedance, low thermal conductivity and low penetrability are less of an issue in this treatment modality [39,40].

Ierardi et al [41] published a study highlighting the advantages of MWA. The authors evaluated the technical success, safety and efficacy of MWA for the treatment of hepatic malignancies in a series of 31 hepatic lesions, with 21 being CRLM. Characteristically, all metastases were $>3 \mathrm{~cm}$ in diameter or were located in close proximity to hepatic vessels, rendering them ineligible for RFA. Overall disease-free survival was 20.5 months and local recurrence rate was $12.9 \%$, endpoints similar to those of RFA treatment. There were no major complications and no procedure-related deaths.

In a recent systematic review, 75 studies were identified that reported outcomes on thermal ablation for CRLM between

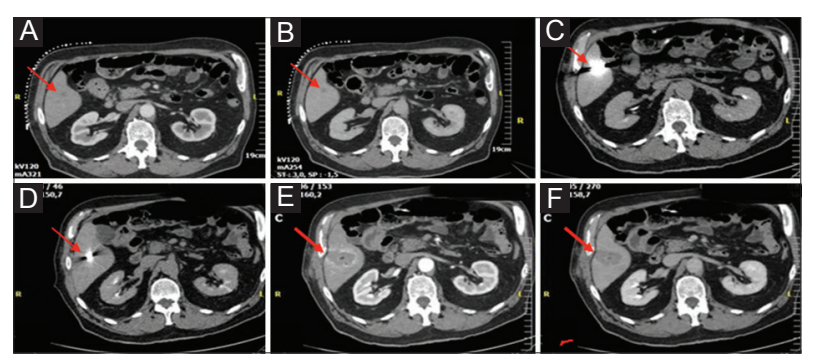

Figure 1 Patient with a small metastatic lesion from colorectal cancer, measuring $1 \mathrm{~cm}$ in maximum diameter, treated with microwave ablation under computed tomographic (CT) guidance. (A) CT scan in arterial phase depicting a hypodense hypovascular lesion in segment VI (red arrow) (B) CT scan in portal venous phase depicting a hypodense lesion with rim enhancement in segment VI (red arrow). (C, D) CT scan during the procedure, note the tip of the microwave antenna within the lesion (red arrow). CT scan immediately post-ablation during arterial (E) and venous (F) phase, depicting the necrotic zone of ablation; note the presence of a peripheral rim of enhancement representing a hypervascular rim of inflammation immediate post ablation (red arrows) 
1994 and 2010. Most studies reported results with RFA (36 studies), with local recurrence rates ranging between $10 \%$ and $31 \%$, whereas studies reporting outcomes of MWA (13 studies) had much lower recurrence (5-13\%) [42].

In a retrospective cohort analysis, Correa-Gallego et al compared the difference in ablation site recurrence between intraoperative MWA and RFA, specifically for CRLM. For MWA the local recurrence rate was 6\%, whereas for RFA it was $20 \%$, a statistically significant difference [43]. Additionally, there are several studies that show no significant difference in OS. In 2015, Huo \& Eslick published the results of a metaanalysis comparing the efficacy and safety of MWA vs. RFA ablation for the treatment of hepatic lesions; overall, 16 studies involving 2062 patients were included. MWA was found to have significantly better 6-year OS than RFA, but this was based on only a few articles ( 3 of 16). MWA and RFA had similar 1-5-year OS, disease-free survival, local recurrence rate and adverse events [44].

Nevertheless, the safety and efficacy of MWA for the treatment of CRLM is widely supported in the current literature (Table 1). Eng et al presented outcomes and recurrence patterns after intraoperative MWA for CRLM. Thirty-three patients were retrospectively analyzed. The maximum size of tumors treated in this study was $5.5 \mathrm{~cm}$. There was only one liver recurrence, while approx. $23 \%$ of patients presented with distant disease alone. OS in this cohort was $35.2 \%$ at 4 years [45]. Wang et al studied the clinical outcomes after ultrasound-guided percutaneous MWA for colorectal metastases. They reported a 3-year survival rate of $78.7 \%$ for colon cancer and $78.6 \%$ for rectal cancer patients. Cumulative recurrence rates in this population were reported as 1-year $27.8 \%$, 2-year $48.4 \%$ and 3 -year recurrence rate of $59.3 \%$ post ablation [46].

Both thermal ablative techniques have been shown in several studies to have high local tumor control with a low recurrence rate, though in the majority of these studies neither method showed a clear benefit in terms of survival outcome. The ease of use, the absence of a need for grounding pads, the shorter overall average ablation time and the theoretical technical advantages over RFA has fueled the shift towards the routine use of MWA. In a recent clinical study by Shady et al concerning ablation with clear margins, the authors concluded that margins $>5 \mathrm{~mm}$ are critical for local tumor control, regardless of the thermal ablation modality used; furthermore, no local tumor progression was noted for margins over $10 \mathrm{~mm}$ [47]. In the same study the authors concluded that, unlike RFA, the efficacy of MWA is not affected in perivascular tumors, suggesting that this type of ablation could be ideal for metastatic lesions close to vessels [47].

\section{Intra-arterial therapies}

Contemporary intra-arterial treatment options for CRLM include TACE, using either emulsions of ethiodized oil and chemotherapy solution (conventional TACE) or drug-eluting beads and chemotherapy solution (DEB-TACE); transarterial radioembolization (TARE), with microspheres labeled with the $\beta$ emitter yttrium-90 $\left({ }^{90} \mathrm{Y}\right)$; hepatic arterial infusion (HAI) of chemotherapy; and percutaneous hepatic perfusion (PHP, also termed chemosaturation) using an organ isolation perfusion system with melphalan. Since the availability of HAI and PHP is limited to only a few centers, in this paper we will focus only on TACE, DEB-TACE and TARE [48].

\section{Indications}

Locoregional intra-arterial therapies are generally indicated for patients with oligometastatic disease, who are not candidates for surgery or other curative locoregional therapies, showing no response, disease progression or toxicity to systemic chemotherapy (Fig. 2). The goal in this group of patients is to achieve long-term disease control, potentially contributing to OS, with well-controlled sites of metastases.

\section{TACE}

The concept of TACE is to infuse chemotherapeutic agents followed by embolic particles into the hepatic arteries supplying the liver tumors, while sparing the surrounding normal hepatic parenchyma. Conventional TACE (c-TACE) has traditionally been performed; it was a common practice to deliver chemotherapeutic agents emulsified with lipiodol, followed by delivery of an embolic agent, often polyvinyl alcohol (PVA) or gelfoam. During the past decades, with the advent of calibrated embolic agents, there was a surge of the use of drug-eluting beads as embolic agents for delivery of the chemotherapeutic solution. The introduction of drug-eluting beads with TACE (DEB-TACE) has been proposed to improve the ability of c-TACE to enhance drug delivery to the tumor,
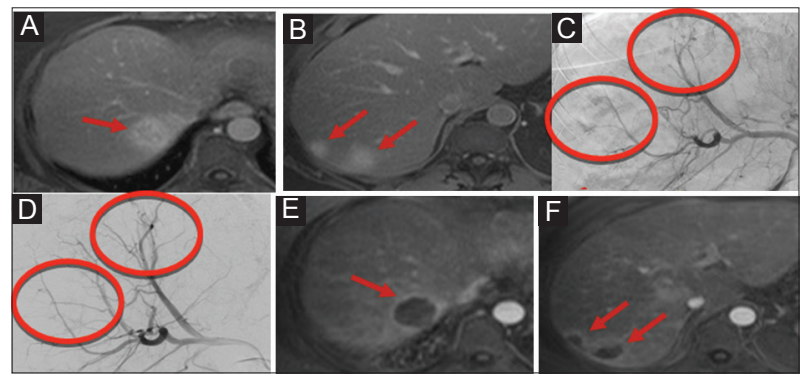

Figure 2 Patient with oligometastatic disease from colorectal cancer treated with liver chemoembolization after failed second line chemotherapy. (A, B) Magnetic resonance (MRI) images after i.v. gadolinium administration depicting 3 hypervascular hepatic lesions in the right lobe (red arrows). (C) Selective hepatic angiogram, depicting the hypervascular lesions in the right liver lobe (red circles). (D) Final selective hepatic angiography after chemoembolization with drug-eluting beads and chemotherapy solution, revealing absence of the pathologic tumor blush (red circles). (E, F) MRI images after i.v. gadolinium administration 1 month after chemoembolization, depicting central necrosis of the lesions with residual minimal peripheral enhancement representing response to the treatment (red arrows) 
theoretically mitigating the systemic drug exposure and thus minimizing side-effects [48].

The safety and efficacy of both c-TACE and DEBTACE have been studied extensively for the treatment of hepatocellular carcinoma (HCC). The Barcelona criteria include TACE as the standard of care for intermediate stage HCC with level of evidence 1A [48]. Because of the proven survival benefit in HCC patients, several series have analyzed the role of TACE in the treatment of secondary hepatic lesions, focusing mainly on colorectal metastases (Table 2). Nowadays it is considered a good therapeutic approach for patients with colorectal cancer and liver-limited disease who fail the available chemotherapeutic options [49-53].

\section{C-TACE}

In 1998, in a phase II trial, Tellez et al evaluated chemoembolization treatment in 30 patients with CRLM who had failed standard-of-care systemic chemotherapy. Radiological responses were seen in $63 \%$ of patients and 95\% experienced a decrease of at least $25 \%$ in their baseline carcinoembryonic antigen level. Median OS for all patients was 8.6 months. The most common toxicity was postembolization syndrome, including fever, nausea, vomiting, and right upper quadrant pain. The authors concluded that c-TACE is a feasible treatment that results in high response rates, with mild-to-moderate toxicity, for patients with CRLM in a salvage setting [54].

Albert et al reported the results of TACE with cisplatin, doxorubicin, mitomycin $\mathrm{C}$, and lipiodol mixture followed by PVA particles in patients with colorectal cancer and unresectable liver dominant disease who had failed systemic chemotherapy. A total of 245 treatments were performed in 121 patients. Patients underwent a mean of two c-TACE sessions. Median time-to-disease progression (TTP) in the treated liver was 5 months, while median TTP anywhere was 3 months. Median survival was 33 months from initial diagnosis and nine months from chemoembolization. OS was significantly better when chemoembolization was performed after first- or second-line systemic therapy than after three to five lines of chemotherapy. Presence of extrahepatic metastases did not adversely affect survival. Albert et al concluded that TACE provided local disease control of liver metastases after $43 \%$ of treatment cycles [55].

Vogl et al reported the results of c-TACE in 463 patients with pretreated unresectable colorectal metastases. Patents were treated with 3 different chemotherapy regimens, including mitomycin $\mathrm{C}$ alone, mitomycin $\mathrm{C}$ with gemcitabine, or mitomycin $\mathrm{C}$ with irinotecan, depending on prior chemotherapy history, mixed with lipiodol and followed by starch microsphere embolization. The 1-year survival rate after chemoembolization was $62 \%$ and 2 -year survival was $28 \%$. No significant survival difference was observed between c-TACE regimens. As with prior studies, the most commonly experienced toxicities of the procedure were symptoms of post-embolization syndrome [56].

\section{DEB-TACE}

DEB-TACE was introduced into clinical trials in 2006, with the rationale of lowering systemic toxicity while increasing the efficacy of chemoembolization through a slower and more sustained release of chemotherapy drugs within the tumor bed. Several studies have been carried out with irinotecanloaded DEB (DEBIRI) for the treatment of CRLM, reporting promising initial data as regards safety and efficacy, especially in patients who had failed systemic chemotherapy.

Martin et al reported the results of DEBIRI in patients with advanced liver metastases from colorectal cancer that failed oxaliplatin- and irinotecan-based systemic chemotherapy and biological agents. The study met its primary endpoints by demonstrating that DEBIRI is safe and well tolerated. Response rate was $66 \%$ at 6 months and $75 \%$ at 12 months. OS was 19 months, with a PFS of 11 months [57].

Aliberti et al reported the results of a phase II study of DEBIRI in 82 patients with CRLM who had failed at least two previous lines of chemotherapy. The response was $78 \%$ at three months, with a median duration of response of 6 months. The median OS was 25 months with a PFS of 8 months [58].

Fiorentini et al conducted the first randomized trial in patients with unresectable CRLM receiving DEBIRI as a salvage therapy, compared to those who underwent FOLFIRI.

Table 2 Literature highlights of chemoembolization for colorectal liver metastases

\begin{tabular}{|c|c|c|c|}
\hline Study $[$ Ref] & Year & Study details & Median OS \\
\hline Vogl et al [53] & 2009 & $\begin{array}{l}\text { TACE, mitomycin } C \text { alone or with gemcitabine } v s \text {. irinotecan Prospective cohort, } \\
463 \text { patients }\end{array}$ & 14 \\
\hline Albert et al [55] & 2011 & TACE, cisplatin, doxorubicin, mitomycin C Retrospective cohort, 121 patients & 9 \\
\hline Martin et al [76] & 2011 & $\begin{array}{l}\text { DEB-TACE (DEBIRI), irinotecan } \\
\text { Prospective cohort, } 55 \text { patient }\end{array}$ & 19 \\
\hline Fiorentini et al [59] & 2012 & $\begin{array}{l}\text { DEB-TACE (DEBIRI), irinotecan Randomized controlled trial, } 74 \text { patients, DEBIRI } \\
v s \text { FOLFIRI }\end{array}$ & 15 \\
\hline Narayanan et al [77] & 2013 & DEB-TACE (DEBIRI) Retrospective cohort, 28 patients & 13,3 \\
\hline Iezzi et al [78] & 2015 & $\begin{array}{l}\text { DEB-TACE (DEBIRI), irinotecan+Capecitabine Prospective phase II Trial, } \\
20 \text { patients }\end{array}$ & 7.3 \\
\hline
\end{tabular}

TACE, transarterial chemoembolization; DEB, drug-eluting beads; DEBIRI, irinotecan-loaded DEB; OS, overall survival, FOLFIRI, FOLinic acid-Fluorouracil-IRInotecan 
All patients had received 2-3 lines of prior chemotherapy. Median OS was longer for patients in the DEBIRI arm (22 vs. 15 months). Compared to patients receiving systemic FOLFIRI, those in the DEBIRI arm also had a greater PFS of 3 months, greater likelihood of objective tumor response (68.6\% vs. $20 \%$ ), and better sustained quality of life ( 8 vs. 3 months, $\mathrm{P}<0.001)$. A major drawback of this study is the omission of oxaliplatin, bevacizumab, cetuximab or panitumumab, as these agents were not part of standard care at the time of the study. When added to FOLFIRI, these agents have demonstrated a greater OS compared with FOLFIRI alone [59].

Three years later, Martin et al published the results of a prospective randomized controlled trial investigating the use of DEBIRI as first-line therapy with simultaneous systemic fluorouracil and oxaliplatin (FOLFOX) and bevacizumab compared with systemic FOLFOX and bevacizumab alone in chemonaive patients with unresectable CRLM. A significant improvement in overall response rates at 6 months $(\mathrm{P}=0.05)$ and liver PFS $(\mathrm{P}=0.05)$ was seen in the DEBIRI arm, which did correlate with a significant improvement in downsizing to resection in the FOLFOX-DEBIRI arm (35\%) vs. the FOLFOXalone control arm $(6 \% ; \mathrm{P}=0.05)$. It failed, however, to show an improvement in PFS and did not present data on OS. This would suggest that DEBIRI may be better reserved for secondline therapy or later; but more studies are definitely needed to determine its role in the treatment algorithm of patients with CRLM [60].

Recently, the results of a systematic review were published reporting the safety and efficacy of DEBIRI-TACE for the treatment of unresectable CRLM. Overall, 13 studies were included, comprising a total of 850 patients. In all, 6 prospective phase I/II trials, 5 retrospective trials and 2 randomized control trials were evaluated. Authors reported a high toxicity rate of $10.1 \%$, which is to be expected in this heavily pretreated population. The weighted average response rates were $56.2 \%$ and $51.1 \%$, according to the RECIST (Response Evaluation Criteria in Solid Tumors) and modified RECIST/EASL (European Association for the Study of the Liver) response criteria, respectively. The weighted average PFS and OS were 8.1 months and 16.8 months, respectively [61].

\section{TARE}

TARE is an intra-arterial, catheter-based technique that, like chemoembolization, delivers high doses of internal radiation to liver tumors. In TARE, microspheres loaded with a radioisotope are deployed to the tumor vasculature, the most common agent being ${ }^{90} \mathrm{Y}$. The most important difference between TACE and TARE is the mechanism of action, i.e. ischemia/chemotherapy vs. irradiation [48].

There is mature and robust evidence that addresses the role of TARE in the treatment of unresectable CRLM. The currently available data have established TARE as a valuable therapeutic salvage option for patients who have failed prior systemic chemotherapy regimens. The literature reports ample data concerning the use of radioembolization in the salvage setting, showing a fairly high response rate of $35-40 \%$ based on size criteria, and even higher responses if we consider functional imaging or tumor markers. The median survival is quite consistent, between 8-14.5 months in all these studies, regardless of the radioembolic agent used (Table 3) [62-66].

More recently, registry-type data were published. Kennedy et al published the results of a multicenter trial from 11 institutions, including 606 patients with CRLM treated with radioembolization with ${ }^{90} \mathrm{Y}$ resin microspheres. Patients had received a median of 2 (range: $0-6$ ) lines of prior chemotherapy

Table 3 Literature highlights of radioembolization for colorectal liver metastases

\begin{tabular}{lcll}
\hline Study [Ref] & Year & Study details & Median OS \\
\hline Kennedy et al [63] & 2006 & $\begin{array}{l}\text { Phase II prospective study } \\
\text { 208 patients }\end{array}$ & 10.5 \\
Sharma et al [79] & 2007 & $\begin{array}{l}\text { Phase I, 20 patients } \\
\text { No prior chemotherapy SIRT+FOLFOX4 }\end{array}$ & $\begin{array}{l}9.3 \\
(14.2 \text { if had only liver-confined disease })\end{array}$ \\
Lewandowski et al [80] & 2014 & $\begin{array}{l}\text { Prospective study } \\
214 \text { patients }\end{array}$ & 10.6 \\
Hickey et al [68] & 2016 & $\begin{array}{l}\text { Retrospective multicenter study, } \\
531 \text { patients }\end{array}$ & 10.6 months \\
\hline
\end{tabular}

Clinical trials

\begin{tabular}{|c|c|c|}
\hline Name & Study details & Outcome \\
\hline $\begin{array}{l}\text { Combined FOXFIRE analysis (SIRFLOX, } \\
\text { FOXFIRE, FOXFIRE GLOBAL) [81] }\end{array}$ & $\begin{array}{l}\text { Phase III randomized controlled trial, } 1103 \text { patients } \\
\text { oxaliplatin-based chemotherapy (FOLFOX: } \\
\text { leucovorin, fluorouracil, and oxaliplatin) vs. } \\
\text { FOLFOX plus single treatment TARE concurrent } \\
\text { with cycle } 1 \text { or } 2 \text { of chemotherapy }\end{array}$ & $\begin{array}{l}\text { No statistically significant difference } \\
\text { in OS and overall progression-free } \\
\text { survival Statistically significant } 4.9 \\
\text { month improvement in median OS } \\
\text { in patients with a right-sided primary } \\
\text { colon cancer }\end{array}$ \\
\hline
\end{tabular}


and $35.1 \%$ had limited extrahepatic metastases. The median OS was 9.6 months from the time of radioembolization [65]. Another multicenter trial by Hickey et al, published in 2016, presented the results of radioembolization with glass microspheres in 531 patients with unresectable colorectal metastases from 8 institutions. Patients had a median OS of 9.6 months from the time of radioembolization. If we consider that the response rate drops to $10 \%$ with third-line systemic chemotherapy and the median survival to 5-8 months, adding radioembolization to the treatment strategy at this time seems to have a clear benefit [68].

The efficacy of TARE as first-line therapy has been studied thoroughly in 3 large trials with similar design, beginning in 2006 with the Sirflox study [69], followed by the Foxfire and the Foxfire global, investigating the effect of radioembolization when added to first-line chemotherapy for the treatment of metastatic colorectal cancer. The combined data from these studies were rather disappointing. Despite an improved response within the liver and liver PFS there was no difference in OS, perhaps because of the progression of extrahepatic disease. Further subanalysis, however, showed that for rightsided primary tumors, which had a poorer prognosis, there was a 4.9-month improvement in OS for those treated with systemic chemotherapy plus TARE compared with those treated with systemic therapy alone, whereas for left-side primaries there was no difference [70]. Based on these data, TARE is currently not recommended as first-line therapy for patients with nonresectable CRLM; a better means of selecting the subgroup of patients who would benefit needs to be defined.

All these local ablative and locoregional therapies have been incorporated in the toolbox of the updated ESMO guidelines for the treatment of metastatic colorectal cancer as potential treatment options for patients with metastatic colorectal cancer. In patients with oligometastatic disease, thermal ablation alone or in combination with surgical resection may be applied, either initially, or possibly after induction treatment with systemic therapy. The aim for these patients is to achieve long-term disease control and potential cure without continued systemic therapies. In patients with more advanced liverlimited disease, chemoembolization and radioembolization are recommended, once other chemotherapeutic options fail, aiming at local tumor control with the ultimate goal being OS prolongation [71].

\section{Concluding remarks}

Colorectal cancer remains one of the most common cancers worldwide, while hepatic metastases account for the greatest proportion of morbidity and mortality from the disease after resection of the primary cancer. Over the past several decades, interventional oncological treatments have greatly evolved and have expanded to play an important role in the management of these patients. As we continue to advance clinically and technologically in the field of interventional oncology, our goal is continue the refinement of regional and systemic therapies aimed at the prolongation of survival of patients with CRLM.
Intra-arterial therapies with ${ }^{90} \mathrm{Y}$ and TACE have been studied thoroughly for converting patients with unresectable HCC to surgical candidates and are worthy of investigation in CRLM. Local ablations have shown an immunoregulatory effect in preclinical and clinical studies. Percutaneous ablation could be used beneficially to optimize the immunotherapy treatments currently being developed for colorectal cancer, in order to reduce both local and remote tumor recurrence. Finally, a combination of percutaneous ablation and intraarterial therapies might confer benefit in patients with CRLM and requires further study.

\section{References}

1. Ferlay J, Steliarova-Foucher E, Lortet-Tieulent J, et al. Cancer incidence and mortality patterns in Europe: estimates for 40 countries in 2012. Eur J Cancer 2013;49:1374-1403.

2. Ferlay J, Soerjomataram I, Dikshit R, et al. Cancer incidence and mortality worldwide: sources, methods and major patterns in GLOBOCAN 2012. Int J Cancer 2015;136:359-386.

3. Torre LA, Bray F, Siegel RL, Ferlay J, Lortet-Tieulent J, Jemal A. Global cancer statistics, 2012. CA Cancer J Clin 2015;65:87-108.

4. Siegel RL, Miller KD, Fedewa SA, et al. Colorectal cancer statistics, 2017. CA Cancer J Clin 2017;67:177-193.

5. Donadon M, Ribero D, Morris-Stiff G, Abdalla EK, Vauthey JN. New paradigm in the management of liver-only metastases from colorectal cancer. Gastrointest Cancer Res 2007;1:20-27.

6. Rees M, Tekkis PP, Welsh FK, O'Rourke T, John TG. Evaluation of long-term survival after hepatic resection for metastatic colorectal cancer: a multifactorial model of 929 patients. Ann Surg 2008;247:125-135.

7. Fernandez FG, Drebin JA, Linehan DC, Dehdashti F, Siegel BA, Strasberg SM. Five-year survival after resection of hepatic metastases from colorectal cancer in patients screened by positron emission tomography with F-18 fluorodeoxyglucose (FDG-PET). Ann Surg 2004;240:438-447.

8. Choti MA, Sitzmann JV, Tiburi MF, et al. Trends in long-term survival following liver resection for hepatic colorectal metastases. Ann Surg 2002;235:759-766.

9. Adam R, Vinet E. Regional treatment of metastasis: surgery of colorectal liver metastases. Ann Oncol 2004;15(Suppl 4):103-106.

10. Misiakos EP, Karidis NP, Kouraklis G. Current treatment for colorectal liver metastases. World J Gastroenterol 2011;17: 4067-4075.

11. Elias D, Viganò L, Orsi F, et al. New perspectives in the treatment of colorectal metastases. Liver Cancer 2016;6:90-98.

12. Van Cutsem E, Vermeil HM, Flamen P, et al. Imaging in colorectal cancer: progress and challenges for the clinicians. Cancers (Basel) 2016;8.

13. Mahnken AH, Pereira PL, de Baère T. Interventional oncologic approaches to liver metastases. Radiology 2013;266:407-430.

14. Gillams A, Goldberg N, Ahmed M, et al. Thermal ablation of colorectal liver metastases: a position paper by an international panel of ablation experts, the Interventional Oncology Sans Frontières meeting 2013. Eur Radiol 2015;25:3438-3454.

15. Rhim H, Goldberg SN, Dodd GD $3^{\text {rd }}$, et al. Essential techniques for successful radio-frequency thermal ablation of malignant hepatic tumors. Radiographics 2001;21:S17-S35.

16. Tatlı S, Tapan U, Morrison PR, Silverman SG. Radiofrequency ablation:techniqueandclinicalapplications.DiagnIntervRadiol2012; 18:508-516. 
17. Solbiati L, Ahmed M, Cova L, Ierace T, Brioschi M, Goldberg SN. Small liver colorectal metastases treated with percutaneous radiofrequency ablation: local response rate and long-term survival with up to 10-year follow-up. Radiology 2012;265:958-968.

18. Gillams AR, Lees WR. Radio-frequency ablation of colorectal liver metastases in 167 patients. Eur Radiol 2004;14:2261-2267.

19. Abdalla EK, Vauthey JN, Ellis LM, et al. Recurrence and outcomes following hepatic resection, radiofrequency ablation, and combined resection/ablation for colorectal liver metastases. Ann Surg 2004;239:818-825.

20. Wang X, Sofocleous CT, Erinjeri JP, et al. Margin size is an independent predictor of local tumor progression after ablation of colon cancer liver metastases. Cardiovasc Intervent Radiol 2013; 36:166-175.

21. Shady W, Petre EN, Gonen M, et al. Percutaneous radiofrequency ablation of colorectal cancer liver metastases: factors affecting outcomes-a 10-year experience at a single center. Radiology 2016; 278:601-611.

22. Van Tilborg AA, Meijerink MR, Sietses C, et al. Long-term results of radiofrequency ablation for unresectable colorectal liver metastases: a potentially curative intervention. Br J Radiol 2011; 84:556-565.

23. Hammill CW, Billingsley KG, Cassera MA, Wolf RF, Ujiki MB, Hansen PD. Outcome after laparoscopic radiofrequency ablation of technically resectable colorectal liver metastases. Ann Surg Oncol 2011;18:1947-1954.

24. Kim KH, Yoon YS, Yu CS, et al. Comparative analysis of radiofrequency ablation and surgical resection for colorectal liver metastases. J Korean Surg Soc 2011;81:25-34.

25. Gillams AR, Lees WR. Five-year survival following radiofrequency ablation of small, solitary, hepatic colorectal metastases. J Vasc Interv Radiol 2008;19:712-717.

26. Otto G, Düber C, Hoppe-Lotichius M, König J, Heise M, Pitton MB. Radiofrequency ablation as first-line treatment in patients with early colorectal liver metastases amenable to surgery. Ann Surg 2010; 251:796-803.

27. Bale R, Widmann G, Schullian P, et al. Percutaneous stereotactic radiofrequencyablation of colorectallivermetastases.EurRadiol2012; 22:930-937.

28. Han Y, Yan D, Xu F, Li X, Cai JQ. Radiofrequency ablation versus liver resection for colorectal cancer liver metastasis: an updated systematic review and meta-analysis. Chin Med J (Engl) 2016; 129:2983-2990.

29. Lee H, Heo JS, Cho YB, et al. Hepatectomy vs radiofrequency ablation for colorectal liver metastasis: a propensity score analysis. World J Gastroenterol 2015;21:3300-3307.

30. Ayav A, Germain A, Marchal F, et al. Radiofrequency ablation of unresectable liver tumors: factors associated with incomplete ablation or local recurrence. Am J Surg 2010;200:435-439.

31. Stang A, Fischbach R, Teichmann W, Bokemeyer C, Braumann D. A systematic review on the clinical benefit and role of radiofrequency ablation as treatment of colorectal liver metastases. Eur J Cancer 2009;45:1748-1756.

32. Ko S, Jo H, Yun S, Park E, Kim S, Seo HI. Comparative analysis of radiofrequency ablation and resection for resectable colorectal liver metastases. World J Gastroenterol 2014;20:525-531.

33. Wu YZ, Li B, Wang T, Wang SJ, Zhou YM. Radiofrequency ablation vs hepatic resection for solitary colorectal liver metastasis: a metaanalysis. World J Gastroenterol 2011;17:4143-4148.

34. Weng M, Zhang Y, Zhou D, et al. Radiofrequency ablation versus resection for colorectal cancer liver metastases: a meta-analysis. PLoS One 2012;7:45493.

35. Agcaoglu O, Aliyev S, Karabulut K, et al. Complementary use of resection and radiofrequency ablation for the treatment of colorectal liver metastases: an analysis of 395 patients. World J Surg 2013; 37:1333-1339.
36. Chua TC, Thornbury K, Saxena A, et al. Radiofrequency ablation as an adjunct to systemic chemotherapy for colorectal pulmonary metastases. Cancer 2010;116:2106-2114.

37. Govaert KM, van Kessel CS, Lolkema M, Theo JM. Ruers, Inne HM. Borel Rinkes. Does radiofrequency ablation add to chemotherapy for unresectable liver metastases? Curr Colorectal Cancer Rep 2012; 8:130-137.

38. Ruers T, Punt C, Van Coevorden F, et al; EORTC Gastro-Intestinal Tract Cancer Group, Arbeitsgruppe Lebermetastasen undtumoren in der Chirurgischen Arbeitsgemeinschaft Onkologie (ALM-CAO) and the National Cancer Research Institute Colorectal Clinical Study Group (NCRI CCSG). Radiofrequency ablation combined with systemic treatment versus systemic treatment alone in patients with non-resectable colorectal liver metastases: a randomized EORTC Intergroup phase II study (EORTC 40004). Ann Oncol 2012;23:2619-2626.

39. Lubner MG, Brace CL, Hinshaw JL, Lee FT Jr. Microwave tumour ablation: mechanism of action, clinical results, and devices. $J$ Vasc Interv Radiol 2010;21 (8 Suppl):S192-S203.

40. Simon CJ, Dupuy DE, Mayo-Smith WW. Microwave ablation: principles and applications. Radiographics 2005;25(Suppl 1):S69-S83.

41. Ierardi AM, Floridi C, Fontana F, et al. Microwave ablation of liver metastases to overcome the limitations of radiofrequency ablation. Radiol Med 2013;118:949-961.

42. Pathak S, Jones R, Tang JM, et al. Ablative therapies for colorectal liver metastases: a systematic review. Colorectal Dis 2011;13:e252-e265.

43. Correa-Gallego C, Fong Y, Gonen M, et al. A retrospective comparison of microwave ablation vs. radiofrequency ablation for colorectal cancer hepatic metastases. Ann Surg Oncol 2014; 21:4278-4283.

44. Huo YR, Eslick GD. Microwave ablation compared to radiofrequency ablation for hepatic lesions: a meta-analysis. J Vasc Interv Radiol 2015;26:1139-1146.

45. Eng OS, Tsang AT, Moore D, et al. Outcomes of microwave ablation for colorectal cancer liver metastases: a single center experience. J Surg Oncol 2015;111:410-413.

46. Wang J, Liang P, Yu J, et al. Clinical outcome of ultrasound-guided percutaneous microwave ablation on colorectal liver metastases. Oncol Lett 2014;8:323-326.

47. Shady W, Petre EN, Do KG, et al. Percutaneous microwave versus radiofrequency ablation of colorectal liver metastases: ablation with clear margins $(\mathrm{a} 0)$ provides the best local tumor control. $J$ Vasc Interv Radiol 2018;29:268-275.

48. Wang DS, Louie JD, Sze DY. Intra-arterial therapies for metastatic colorectal cancer. Semin Intervent Radiol 2013;30:12-20.

49. Facciorusso A, Licinio R, Muscatiello N, Di Leo A, Barone M. Transarterial chemoembolization: Evidences from the literature and applications in hepatocellular carcinoma patients. World $J$ Hepatol 2015;7:2009-2019.

50. Bala MM, Mituś JW, Riemsma RP, et al. Transarterial (chemo) embolisation versus chemotherapy for colorectal cancer liver metastases. Cochrane Database Syst Rev 2017;8:CD012757.

51. Martinelli DJ, Wadler S, Bakal CW, et al. Utility of embolization or chemoembolization as second-line treatment in patients with advanced or recurrent colorectal carcinoma. Cancer 1994; 74:1706-1712.

52. Scevola G, Loreni G, Rastelli M, Sposato S, Ramponi S, Miele V. Third-line treatment of colorectal liver metastases using DEBIRI chemoembolization. Med Oncol 2017;34:37.

53. Vogl T), Gruber T, Balzer JO, Eichler K, Hammerstingl R, Zangos S. Repeated transarterial chemoembolization in the treatment of liver metastases of colorectal cancer: prospective study. Radiology 2009;250:281-289.

54. Tellez $\mathrm{C}$, Benson $\mathrm{AB} 3^{\text {rd }}$, Lyster MT, et al. Phase II trial of chemoembolization for the treatment of metastatic colorectal carcinoma to the liver and review of the literature. Cancer 
1998;82:1250-1259.

55. Albert M, Kiefer MV, Sun W, et al. Chemoembolization of colorectal liver metastases with cisplatin, doxorubicin, mitomycin C, ethiodol, and polyvinyl alcohol. Cancer 2011;117:343-352.

56. Vogl TJ, Zangos S, Eichler K, et al. Colorectal liver metastases: regional chemotherapy via transarterial chemoembolization (TACE) and hepatic chemoperfusion: an update. Eur Radiol 2007; 17:1025-1034.

57. Martin RC, Robbins K, Tomalty D, et al. Transarterial chemoembolisation (TACE) using irinotecan-loaded beads for the treatment of unresectable metastases to the liver in patients with colorectal cancer: an interim report. World J Surg Oncol 2009;7:80.

58. Aliberti C, Fiorentini G, Muzzio PC, et al. Trans-arterial chemoembolization of metastatic colorectal carcinoma to the liver adopting DC $\mathrm{Bead}^{\circledR}$, drug-eluting bead loaded with irinotecan: results of a phase II clinical study. Anticancer Res 2011; 31:4581-4587.

59. Fiorentini G, Aliberti C, Tilli M, et al. Intra-arterial infusion of irinotecan-loaded drug-eluting beads (DEBIRI) versus intravenous therapy (FOLFIRI) for hepatic metastases from colorectal cancer: final results of a phase III study. Anticancer Res 2012;32:1387-1395.

60. Martin RCG, Scoggins CR, Schreeder M, et al. Randomized controlled trial of irinotecan drug-eluting beads with simultaneous FOLFOX and bevacizumab for patients with unresectable colorectal liver-limited metastasis. Cancer 2015;121:3649-3658.

61. Akinwande O, Dendy M, Ludwig JM, Kim HS. Hepatic intraarterial injection of irinotecan drug eluting beads (DEBIRI) for patients with unresectable colorectal liver metastases: A systematic review. Surg Oncol 2017;26:268-275.

62. MulcahyMF, LewandowskiRJ, IbrahimSM, etal. Radioembolization of colorectal hepatic metastases using yttrium-90 microspheres. Cancer 2009;115:1849-1858.

63. Kennedy AS, Coldwell D, Nutting C, et al. Resin 90Y-microsphere brachytherapy for unresectable colorectal liver metastases: modern USA experience. Int J Radiat Oncol Biol Phys 2006;65:412-425.

64. Cianni R, Urigo C, Notarianni E, et al. Selective internal radiation therapy with SIR-spheres for the treatment of unresectable colorectal hepatic metastases. Cardiovasc Intervent Radiol 2009; 32:1179-1186

65. Evans KA, Richardson MG, Pavlakis N, Morris DL, Liauw W, Bester L. Survival outcomes of a salvage patient population after radioembolization of hepatic metastases with yttrium-90 microspheres. J Vasc Interv Radiol 2010;21:1521-1526.

66. Lewandowski RJ, Thurston KG, Goin JE, et al. 90Y microsphere (TheraSphere) treatment for unresectable colorectal cancer metastases of the liver: response to treatment at targeted doses of 135-150 Gy as measured by [18F]fluorodeoxyglucose positron emission tomography and computed tomographic imaging. J Vasc Interv Radiol 2005;16:1641-1651.

67. Kennedy AS, Ball D, Cohen SJ, et al. Multicenter evaluation of the safety and efficacy of radioembolization in patients with unresectable colorectal liver metastases selected as candidates for (90)Y resin microspheres. J Gastrointest Oncol 2015;6:134-142.

68. Hickey R, Lewandowski RJ, Prudhomme T, et al. 90Y radioembolization of colorectal hepatic metastases using glass microspheres: safety and survival outcomes from a 531-patient multicenter study. J Nucl Med 2016;57:665-671.

69. Van Hazel GA, Heinemann V, Sharma NK, et al. SIRFLOX: randomized phase III trial Comparing first-line mFOLFOX6 (plus or minus Bevacizumab) versus mFOLFOX6 (plus or minus Bevacizumab) plus selective internal radiation therapy in patients with metastatic colorectal cancer. J Clin Oncol 2016;34:1723-1731.

70. Wasan HS, Gibbs P, Sharma NK, et al; FOXFIRE-Global trial investigators. First-line selective internal radiotherapy plus chemotherapy versus chemotherapy alone in patients with liver metastases from colorectal cancer (FOXFIRE, SIRFLOX, and FOXFIRE-Global): a combined analysis of three multicentre, randomised, phase 3 trials. Lancet Oncol 2017;18:1159-1171.

71. Van Cutsem E, Cervantes A, Adam R, et al. ESMO consensus guidelines for the management of patients with metastatic colorectal cancer. Ann Oncol 2016;27:1386-1422.

72. Hilderbrand P, Kleemann M, Roblick UJ, et al. Radiofrequencyablation of unresectable primary and secondary liver tumors: results in 88 patients. Langenbecks Arch Surg 2006;391:118-123.

73. Gillams AR, Lees WR. Five-year survival in 309 patients with colorectal liver metastases treated with radiofrequency ablation. Eur Radiol 2009;19:1206-1213.

74. Sofocleous CT, Petre EN, Gonen M et al. CT-guided radiofrequency ablation as a salvage treatment of colorectal cancer hepatic metastases developing after hepatectomy. J Vasc Interv Radiol 2011; 22:755-761.

75. Bonne L, De Paepe K, Fotiadis N, et al. Percutaneous radiofrequency versus microwave ablation for the treatment of colorectal liver metastases. Journal of Clinical Oncology 2018;36:401-401.

76. Martin RC, Joshi J, Robbins K, et al. Hepatic intra-arterial injection of drug-eluting bead, irinotecan (DEBIRI) in unresectable colorectal liver metastases refractory to systemic chemotherapy: results of multi-institutional study. Ann Surg Oncol 2011;18:192-198.

77. Narayanan G, Barbery K, Suthar R, Guerrero G, Arora G. Transarterial chemoembolization using DEBIRI for treatment of hepatic metastases from colorectal cancer. Anticancer Res 2013; 33:2077-2083.

78. Iezzi R, Marsico VA, Guerra A et al. Trans-arterial chemoembolization with irinotecan-loaded drug-eluting beads (DEBIRI) and capecitabine in refractory liver prevalent colorectal metastases: a phase II single-center study. Cardiovasc Intervent Radiol 2015;38:1523-1531.

79. Sharma RA, Van Hazel GA, Morgan B, et al. Radioembolization of liver metastases from colorectal cancer using yttrium-90 microspheres with concomitant systemic oxaliplatin, fluorouracil, and leucovorin chemotherapy. J Clin Oncol 2007;25:1099-1106.

80. Lewandowski RJ, Memon K, Mulcahy MF et al. Twelve-year experience of radioembolization for colorectal hepatic metastases in 214 patients: survival by era and chemotherapy. Eur J Nucl Med Mol Imaging 2014;41:1861-1869.

81. H. Wasan, R. Sharma, V. Heinemann et al. FOXFIRE-SIRFLOXFOXFIRE Global prospective randomised studies of first-line selective internal radiotherapy (SIRT) in patients with liver metastases from colorectal cancer. Ann Oncol 2017;28:605-649. 